\title{
A BASE NACIONAL COMUM CURRICULAR (BNCC) E A EDUCAÇÃO BÁSICA: APRENDER A APRENDER COMO CAMINHO PARA APRENDER A PENSAR ${ }^{1}$
}

\author{
THE COMMON NATIONAL CURRICULUM BASE (BNCC) AND BASIC EDUCATION: \\ LEARNING TO LEARN AS A WAY TO LEARN TO THINK \\ EL COMMONNATIONALCURRICULUM BASE (BNCC) Y LA EDUCACIÓN BÁSICA:
APRENDER A APRENDER COMO UNA FORMA DE APRENDER A PENSAR
}

Rogério Rodrigues 2

\section{RESUMO}

Este ensaio tem como objetivo analisar as possíveis relações entre o ensinar e 0 aprender na proposição que se encontra presente na Base Nacional Comum Curricular (BNCC). A partir do BNCC, a pergunta central deste ensaio é se é viável a proposição de usar máquina de calcular no ensino fundamenta para 0 ensino da matemática. 0 método utilizado para a construção deste estudo tem como proposição investigativa a teoria crítica para analisar o campo educacional. Conclui-se que 0 ato de inserir, precocemente, o uso da máquina de calcular no ensino da matemática não se encontra fundamentado nas teorias de aprendizagem e, portanto, pode indicar apenas elemento de modismo pedagógico relacionado ao uso das tecnologias digitais. Torna-se preocupante a precarização do ensino escolar, em que os resultados dessas ações do modismo pedagógico podem impedir a constituição do sujeito reflexivo no permanente trabalho na experiência do pensamento como lugar do aprender a pensar.

PALAVRAS-CHAVE: Filosofia da Educação; Educação básica; Ensino; Aprendizagem; Máquina de Calcular.

\begin{abstract}
This essay aims to analyze the possible relationships between teaching and learning in the proposition that is present in the National Common Curricular Base (BNCC). From the BNCC, the central question of this essay is whether the proposition of using a calculating machine in elementary school segment for the teaching of mathematics is viable. The method used for the construction of this study has as an investigative proposition the critical theory to analyze the educational field. It is concluded that the act of inserting, early, the use of the calculating machine in the teaching of mathematics is not based on learning theories and, therefore, can indicate only element of pedagogical fad related to the use of digital technologies. It is worrying the precariousness of school education, in which the results of these actions of pedagogical fad may prevent the constitution of the reflective subject in the permanent work in the experience of thinking as a place of learning to think.
\end{abstract}

KEYWORDS: Philosophy of Education; Basic education; Teaching; Learning; Calculator.

\section{RESUMEN}

Este ensayo tiene como objetivo analizar las posibles relaciones entre la enseñanza y el aprendizaje en la propuesta que está presente en la Base Curricular Común Nacional (BNCC). Desde el BNCC, la pregunta central de este ensayo es si la propuesta de usar una máquina calculadora en la escuela primaria para la enseñanza de las matemáticas es viable. El método utilizado para la construcción de este estudio tiene como propuesta investigativa la teoría crítica para analizar el campo educativo. Se concluye que el acto de insertar, temprano, el uso de la máquina calculadora en la enseñanza de las matemáticas no se basa en teorías del aprendizaje y, por lo tanto, puede indicar solo un elemento de moda pedagógica relacionado con el uso de tecnologías digitales. Es preocupante la precariedad de la educación escolar,

\footnotetext{
1 Agradeço à Universidade Federal de Itajubá (UNIFEI) e aos seus alunos do curso de licenciatura em Física, Química, Matemática e Biologia.

2 Universidade Federal de Itajubá. Itajubá, Minas Gerais, Brasil. E-mail: rrunifei@hotmail.com 
en la que los resultados de estas acciones de moda pedagógica pueden evitar la constitución del sujeto reflexivo en el trabajo permanente en la experiencia del pensamiento como lugar de aprender a pensar.

PALABRAS CLAVE: Filosofía de la educación; Educación básica; Enseñando; Aprendizaje; Calculadora.

\section{INTRODUÇÃO: APRENDER A PENSAR E 0 USO DA MÁQUINA CALCULADORA NO ENSINO DA MATEMÁTICA}

Torna-se muito interessante a expressão "educação básica", que se refere, diretamente,à organização do sistema escolar. Essa fase remete, de modo direto,à organização do tempo escolar como lugar específico em que se definem os processos de formação do sujeito para se inserir na cultura escolar.

Nesses termos, a educação básica se apresenta, ao longo do tempo, em etapas divididas do processo formativo na educação infantil, no ensino fundamental e no ensino médio. Cada uma dessas etapas constitui pressupostos teóricos em termos de teoria educativa do que se deve ser ensinado como meta do processo de escolarização em que o sujeito entra diretamente em contato com a cultura científica numa proposição organizada em suas metas de ensino e aprendizagem (BRASIL, SEM DATA).

O ensino fundamental encontra-se dividido em duas etapas: o I e o II. Isso se torna uma importante divisão, pois essa segmentação está pautada numa distinção que se refere ao modo de iniciar o sujeito no campo da cultura escolar. A primeira distinção, que ocorre no fundamental I é a presença somente do professor polivalente, que ensina diversas matérias do assunto escolar, pois, no fundamental II, temos a existência do professor especialista para cada componente do currículo escolar.

Entretanto, podemos afirmar que assuntos de especialistas já se encontram presentes desde a educação infantil, pois diversos conceitos da ciência já são apresentados, na forma lúdica, às crianças nos jogos e brincadeiras (XXX - retirado a fonte 0 autor para não identificar, 2018). O que se busca, primordialmente, é que a criança possa começar a se inserir na rotina escolar e iniciar os processos básicos de alfabetização, lógica de conceitos das ciências básicas e uso coordenado do corpo.

O ensino fundamental se encontra dividido em duas etapas: no I, do primeiro até o quinto ano; e o II, que se inicia no sexto e perdura até o nono ano, em que a criança já apresenta um maior contato com os conceitos da ciência. No transcorrer dos anos, o aluno se prepara para o aprofundamento específico do conteúdo, primordialmente, no ensino médio, que passa ser um preparativo para o ingresso no ensino superior.

Esse encadeamento lógico do ensinar e aprender conduz o sujeito numa progressão lógica na construção do conceito como elemento significativo para se compreender a dinâmica 
da realidade. Isso seria o ponto que diferencia a cultura escolar nessas diversas etapas do ensino escolar e que, inclusive, organiza-se em decorrência da concepção de Psicologia da Educação que se apresenta como forma de organizar a didática em torno do ensinar e do aprender.

Apesar de toda esta situação organizacional do ensino escolar, tivemos uma ruptura da rotina no início do ano letivo de 2020, mais propriamente, a partir da segunda quinzena do mês de março, em que, em decorrência da pandemia do novo coronavírus, todas as escolas do mundo foram fechadas (PINTO, 2020). Desse modo, para prevenção ao contágio desse vírus, foi adotada a medida de que todos deveriam ficar em casa, inclusive a população escolar (SEM AUTOR, 2020).

Neste quadro de confinamento, diversas famílias tiveram que aplicar o ensino escolar em casa no novo normal para manter a distância entre os sujeitos estabelecidos pelo isolamento social, para se evitar o contágio pelo também novo coronavírus.

No período de ficarem em casa, várias famílias puderam construir um contato direto como os conteúdos e métodos de ensino da escola na posição de mediador das tarefas enviadas pela unidade escolar para o ensino e a aprendizagem na lição.

Neste contexto de confinamento, fomos informados por um colega que, durante 0 acompanhamento da lição realizada pelo seu filho, em casa, teve o contato com o livro didático de matemática do quarto ano do ensino fundamental e encontrou o enunciado que se pede para fazer uma conta em que "[...] peça a um colega que as resolva utilizando a calculadora". Mesmo que seja para o "colega" ao resolver usando a calculadora, faça uma correção das questões resolvidas pelo outro aluno sem o uso da calculadora isso se apresenta em nossa concepção um modelo de ensino que retira a possibilidade de pensamento crítico no uso dos números.

Essa informação de usar máquina de calculadora no quarto ano do fundamental se encontra num livro que tem como a referência à BNCC. Isso foi, um verdadeiro espanto, pois não tinha o conhecimento da utilização desse recurso pedagógico (máquina de calcular) para 0 ensino da matemática e se isso torna possível encontrar alguma lógica para o uso deste instrumento eletrônico, principalmente, no sentido de o sujeito aprender a pensar as operações matemáticas.

Não pude deixar de lembrar, diretamente, do meu ensino primário, em que fazíamos as contas com o auxílio do ábaco, que é um instrumento simples, que permite contar unidades, dezenas, centenas, enfim, a calcular, mas aprendendo a pensar nos números. Portanto, temos uma diferença entre uma máquina de calcular, que não permite pensar os números e o referido 
instrumento tecnológico (ábaco), que permite realizar as contas com o trabalho do pensamento em relação às ordens das casas dos números e a contagem das referidas unidades.

Nesse contexto, fiquei indignado com a informação referente ao uso da máquina eletrônica de calcular, que se apresenta também como instrumento tecnológico, mas que não permite ao sujeito nenhuma forma de cálculo e torna o sujeito passivo na ação do pensamento.

Em relação a esse assunto, coube a mim a fazer um parecer sobre esta questão em decorrência de ser professor de Psicologia da Educação e Estrutura e Funcionamento do Ensino Fundamental e Médio nos cursos de licenciaturas e, inclusive, para os futuros professores de matemáticas.

A referida questão sobre o uso da máquina de calcular no quarto ano do ensino fundamental me permitiu analisar aspectos relacionados às teorias da aprendizagem. Portanto, como profissional e pesquisador na área da educação, avalio diversos artigos científicos que são publicados em revistas especializadas e não seria nada diferente analisar o referido livro didático de matemática e a proposição do BNCC, que insere o uso da máquina de calcular para o quarto do ano do ensino fundamental. Entretanto, refiro-me a esse assunto no sentido de discutir a situação, respeitando a autonomia da unidade escolar em que prevalece a escolha do seu material pedagógico. Inclusive, cabe ao professor a plena autonomia e liberdade de expressão no modo de conduzir o ensino.

O que se pretende analisar, neste ensaio, seria o paradoxo referente ao uso da calculadora no ensino da matemática para o quarto ano do Fundamental. Pude observar que são diversas as fontes que discutem o uso da calculadora nas aulas de matemática (KISTEMANN, 2020). Importante deixar claro que não sou contra o uso das tecnologias digitais e, inclusive, fazemos o uso delas em nosso cotidiano em tarefas que demandam rapidez em nossas ações.

Entretanto, o que estamos analisando é a forma do ensinar e do aprender ao lidar com operações numéricas como pressuposto para a estrutura do pensamento. 0 ponto de divergência sobre o uso da máquina de calcular é a indicação do livro didático de matemática para o uso desse instrumento para o quarto ano do ensino fundamental.

Nesse ponto, cabe colocar em evidência a minha discordância radical sobre essa didática no ensino da matemática no quarto ano do ensino fundamental, primordialmente, que não se deve usar a máquina calculadora para crianças realizarem as operações numéricas. Para tanto, vou atribuir algumas outras referências para a discordância teórica em relação a este assunto. Vou começar pela Lei de Diretrizes e Bases da Educação, que, em seu artigo: 
básica do cidadão, mediante: I - o desenvolvimento da capacidade de aprender, tendo como meios básicos o pleno domínio da leitura, da escrita e do cálculo (BRASIL, 1996).

Cabe agora compreender: o que seria o desenvolvimento da capacidade de aprender 0 cálculo matemático? Para responder a essa questão, podemos recorrer à Base Nacional Comum Curricular (BNCC), que estabelece as "Competências específicas de matemática para o ensino fundamental", em que até podemos observar a oferta de uso de tecnologias digitais:

[...] 5. Utilizar processos e ferramentas matemáticas, inclusive tecnologias digitais disponíveis, para modelar e resolver problemas cotidianos, sociais e de outras áreas de conhecimento, validando estratégias e resultados. [...] No Ensino Fundamental Anos Iniciais, a expectativa em relação a essa temática é que os alunos resolvam problemas com números naturais e números racionais cuja representação decimal é finita, envolvendo diferentes significados das operações, argumentem e justifiquem os procedimentos utilizados para a resolução e avaliem a plausibilidade dos resultados encontrados. No tocante aos cálculos, espera-se que os alunos desenvolvam diferentes estratégias para a obtenção dos resultados, sobretudo por estimativa e cálculo mental, além de algoritmos e uso de calculadoras. (BRASIL, SEM DATA, $p$. 263-264).

Fica em evidência a adesão da Base Nacional Comum Curricular à indicação da tecnologia digital e, inclusive, a menção para o uso da calculadora, na BNCC, para o ensino da matemática no Ensino Fundamental. Ademais, pudemos observar, nas determinações das habilidades requeridas na BNCC, que o uso da tecnologia digital se apresenta no terceiro ano do fundamental para suporte no estudo de figuras geométricas, em que se deve "(EF03MA16) Reconhecer figuras congruentes, usando sobreposição e desenhos em malhas quadriculadas ou triangulares, incluindo o uso de tecnologias digitais (BRASIL, SEM DATA, p. 289). Já o uso da máquina de calcular como elemento de tecnologia digital se apresenta no quarto e quinto ano do fundamental, em que:

(EF04MA13) Reconhecer, por meio de investigações, utilizando a calculadora quando necessário, as relações inversas entre as operações de adição e de subtração e de multiplicação e de divisão, para aplicá-las na resolução de problemas (BRASIL, SEM DATA, p. 291)

(EF05MA06) Associar as representações 10\%, 25\%, 50\%, 75\% e 100\% respectivamente à décima parte, quarta parte, metade, três quartos e um inteiro, para calcular porcentagens, utilizando estratégias pessoais, cálculo mental e calculadora, em contextos de educação financeira, entre outros (BRASIL, SEM DATA, p. 295).

No ensino fundamental, o uso da máquina de calcular no ensino da matemática se apresenta no sexto e sétimo ano:

(EF06MA03) Resolver e elaborar problemas que envolvam cálculos (mentais ou escritos, exatos ou aproximados) com números naturais, por meio de estratégias variadas, com compreensão dos processos neles envolvidos com e sem uso de calculadora (BRASIL, SEM DATA, p. 297). 
(EF06MA09) Resolver e elaborar problemas que envolvam o cálculo da fração de uma quantidade e cujo resultado seja um número natural, com e sem uso de calculadora (BRASIL, SEM DATA, p. 301).

(EF06MA11) Resolver e elaborar problemas com números racionais positivos na representação decimal, envolvendo as quatro operações fundamentais e a potenciação, por meio de estratégias diversas, utilizando estimativas e arredondamentos para verificar a razoabilidade de respostas, com e sem uso de calculadora (BRASIL, SEM DATA, p. 301).

(EF06MA13) Resolver e elaborar problemas que envolvam porcentagens, com base na ideia de proporcionalidade, sem fazer uso da "regra de três", utilizando estratégias pessoais, cálculo mental e calculadora, em contextos de educação financeira, entre outros. (BRASIL, SEM DATA, p. 301).

(EF07MA02) Resolver e elaborar problemas que envolvam porcentagens, como os que lidam com acréscimos e decréscimos simples, utilizando estratégias pessoais, cálculo mental e calculadora, no contexto de educação financeira, entre outros (BRASIL, SEM DATA, p. 307).

Baseado nessa simples consulta ao BCCN torna-se possível expressar a demanda pelo uso da máquina de calcular e que o referido texto do livro didático do qual o pai do aluno reclama encontra-se alinhado com a referida proposta. Cabe analisar os motivos que fundamentam 0 incentivo no uso das tecnologias digitais no ensino da matemática e que aplicam o uso da máquina de calcular.

A nossa posição sobre esse assunto encontra-se em contraposição ao presente no BNCC, pois compreendemos que ensinar a matemática para as crianças no ensino fundamental se constitui numa lógica de operações mentais que demandam um longo trabalho do pensamento. Em nossa interpretação, ocorre uma grande distinção sobre o que seria o uso das tecnologias digitais e o uso da máquina de calcular.

Pode-se elaborar um curso para o ensino da matemática, em que o aluno possa se envolver, em diversos jogos no campo das tecnologias digitais ou outras atividades sem fazer 0 uso da máquina de calcular. Compreendemos que ensinar a matemática é permitir ao sujeito elaborar os números e, primordialmente, as relações de adição, subtração, multiplicação, divisão, enfim, os diversos conteúdos que compõem a cultura escolar nessa referida área do conhecimento.

Em relação à cultura escolar, a nossa perspectiva teórica para essa tomada de posição se fundamenta numa compreensão de que deveria se privilegiar o trabalho do pensamento $e$ isso se constitui, primordialmente, na compreensão de Arendt (2011), que afirma:

Não se pode educar sem ao mesmo tempo ensinar; uma educação sem aprendizagem é vazia e, portanto, degenera, com muita facilidade, em retórica moral e emocional. É muito fácil, porém, ensinar sem educar, e pode-se aprender durante o dia todo sem por isso ser educado. (ARENDT, 2011, p. 246-247). 
Fiquei analisando o quanto o ensino da matemática pode se encontrar vazio de conceito no ensino do fundamental ao expor o sujeito à máquina de calcular. Compreendemos que se torna importante demarcar a total indignação sobre este modo operante que aliena o sujeito por completo no processo de estabelecer uma experiência do trabalho do pensamento em termos numéricos.

Partimos do pressuposto de que o ensino dos fundamentos da matemática para as crianças se encontra nos detalhes em se tratando da didática de se iniciar no campo da cultura escolar e essa retomada de cuidado é que fundamenta o motivo que compreendemos que não se deve usar a máquina calculadora no ensino da matemática como elemento fundamental para a construção do pensamento crítico.

\section{DISCUSSÃO - A FORMAÇÃO ESCOLAR E A EXPERIÊNCIA DO PENSAMENTO}

Para discutir o tema em questão sobre o ensino da matemática e a nossa oposição sobre o uso da máquina de calcular no ensino fundamental, prosseguiremos por três distintos caminhos no sentido de analisar a formação escolar e a experiência do pensamento. 0 primeiro caminho será observar como se encontra o Brasil em relação a outros países na avaliação em matemática. O segundo será uma consulta direta a gestores públicos sobre o referido assunto relacionado ao uso da máquina de calcular no ensino fundamental; o terceiro e último será analisar esta questão a partir da atividade educativa e, para fundamentar essa proposição, iremos nos pautar na teoria do conhecimento de Piaget (1974) e na concepção de ensino de Vygotsky (1988).

Para o primeiro item, que se trata de países que apresentam bom desempenho no ensino da matemática, selecionaremos como critério o PISA (Programme for InternationalStudentAssessment), que avalia o campo de leitura, ciências e matemática. Em decorrência da longa lista de setenta e nove países participantes, optamos por colocar os seis primeiros países e os demais que se encontram no continente americano para analisarmos a classificação em matemática:

\section{País}

Pontuação

1. Pequim, Xangai, Jiangsu e Guangdong (China)

2. Singapura

3. Macau (China) 
5. Taipei chinesa

6. Japão

38. Estados Unidos*

59. Uruguai

418

60. Chile

62. México

64. Costa Rica 402

65. Peru 400

70. Colômbia 391

71 Brasil

72 Argentina 379

77 Panamá 353

79. República Dominicana 325 (BERMÚDEZ, 2020).

Podemos observar que, na referida classificação do PISA, o Brasil se encontra na posição $71^{\circ}$ e a última posição dessa avaliação é a $79^{\circ}$, em que se encontra a República Dominicana. Essa classificação indica a baixa qualidade na educação em matemática do Brasil que ficou quase em último lugar. 0 relatório completo pode ser acessado diretamente no site do Instituto Nacional de Estudos e Pesquisas Educacionais (INEP) (BRASIL, 2020a).

Essa classificação do Brasil no PISA permite compreender que estamos diante de algum problema referente à transmissão do conceito no ensino da matemática e isso é algo que se apresenta como ponto a ser discutido entre os educadores de outros saberes também avaliados na leitura e nas ciências em que o Brasil também se classifica na referida avaliação com baixo rendimento dos alunos (BRASIL, 2020a).

O melhor país em matemática na avaliação do PISA é a China e isso nos leva a tentar compreender o que se passa no modo como eles transmitem o conceito no campo da cultura escolar em que

Desde a pré-escola, as crianças chinesas são submetidas a aulas que priorizam a aquisição do conhecimento por métodos passivos. Os alunos devem respeitar a hierarquia - sendo a supremacia do professor incontestável - e buscar reproduzir, da maneira mais exata possível, os ensinamentos prescritos nas aulas e nos livros 
adotados por cada classe. Exercícios de matemática são repetidos à exaustão, bem como a memorização de textos clássicos chineses, até que o aluno demonstre ter assimilado com perfeição o conteúdo transmitido. A valorização do mérito e a forte concorrência fazem com que os bons alunos sejam recompensados à medida que superam os demais e conquistam as notas mais altas nos exames orais e escritos. $\mathrm{Na}$ melhor tradição dos mandarins, o estudo é o caminho por excelência para a ascensão social (DIAS, 2004, p. 147).

Torna-se importante que compreendamos as diferenças culturais que cada lugar possui em termos de educar o outro, mas é preciso reconhecer que, no Brasil, perde-se, na transmissão do conceito, a autoridade do professor e os sujeitos se embaraçam nas contas quando e, principalmente, perdem-se na transmissão da experiência do pensamento no uso dos números. No caso do uso da máquina de calcular, isso se apresenta, mais propriamente, na ausência da experiência com os números no modo de pensar a matemática.

Passamos para o segundo ponto e, portanto, trata-sede perguntar diretamente para os gestores da educação, para que seus especialistas possam dizer algo sobre o uso da máquina de calcular no quarto ano do ensino fundamental. Por esse outro caminho, foi realizada uma consulta direta ao Ministério da Educação do Brasil (MEC), mais propriamente, ao setor de Coordenação-Geral de Materiais Didáticos - COGEAM sobre a questão referente ao uso da máquina de calcular no quarto ano do ensino fundamental. Em relação a esta consulta obtivemos a resposta de que a obra didática citada "[...] não foi aprovada de acordo com os critérios estabelecidos no edital, portanto, não faz parte do Guia Digital PNLD 2019". Entretanto, não respondeu sobre a proposição para o uso da máquina de calcular, que se encontra presente na BNCC. Agora, fica outra questão: como um livro não aprovado no Programa Nacional do Livro e do Material Didático (PNLD) pode ser recomendado para o uso em demais escolas? Cabe lembrar que o referido programa (PNLD) é destinado para se constituir em:

Os materiais distribuídos pelo MEC às escolas públicas de educação básica do país são escolhidos pelas escolas, desde que inscritos no PNLD e aprovados em avaliações pedagógicas coordenadas pelo Ministério da Educação e que conta com a participação de Comissões Técnica específica, integrada por especialistas das diferentes áreas do conhecimento correlatas, cuja vigência corresponderá ao ciclo a que se referir o processo de avaliação (BRASIL, 2020b).

Em relação a essa questão, fiz uma consulta direta na editora do referido livro didático que foi a fonte de reclamação do pai do aluno, com a seguinte pergunta: "Consta um selo na capa do livro - BNCC. Entretanto, não observo o referido livro na relação dos livros do Guia digital - PNLD". Sobre esse questionamento, não obtive uma resposta direta da editora. Aqui, pode ser que o referido livro não tenha se inscrito para participar no PNLD. 
O terceiro ponto sobre a atividade educativa será analisar esta questão pela opção do construtivismo, que se apresenta de modo hegemônico a partir da teoria do conhecimento de Piaget (1974) e na concepção de ensino de Vygotsky (1988).

O construtivismo possui como fundamento que o conceito se elabora a partir da significação que se apresenta para o sujeito. Nesse sentido, a escola tem a função de conduzir esse processo de significação que, em termos do pensamento numérico, significa atender a uma determinada lógica do pensamento.

Em se tratando da construção da lógica do pensamento, para Piaget (1974), seria algo que podemos definir como teoria do conhecimento, mais propriamente como o sujeito constrói seu pensamento. Para ele, esse processo se encontra em etapas que se apresentam no desenvolvimento do sujeito e que se divide em sensório-motora, que vai até os 18 meses; préoperatória, que vai até 7 ou 8 anos; operações concretas, que fica entre 7 e 12 anos e, por último, as operações proporcionais ou formais dos 12 anos em diante (PIAGET, 1974). Em cada uma dessas etapas, encontra-se um estágio do pensamento em que, na etapa sensório-motor, encontramos, no sujeito, até os dezoito meses

[...] ações que constituem o pensamento, essas ações interiorizadas, é necessário aprender primeiramente a executá-las materialmente; elas exigem primeiramente todo um sistema de ações efetivas, de ações materiais. Pensar é, por exemplo, classificar, ou ordenar, ou correlacionar; é reunir, ou dissociar, etc. Mas todas essas operações, é necessário primeiramente, executá-las materialmente em ações para em seguida ser capaz de construir em pensamento (PIAGET, 1974, p. 344-345).

Passamos, agora, para a etapa seguinte, o pré-operatório, quando ocorre a situação em que

Por volta de um ano e meio, dois anos, um acontecimento considerável se produz no desenvolvimento intelectual da criança. É agora que aparece a capacidade de representar alguma coisa por meio de outra coisa, o que chamamos de função simbólica (PIAGET, 1974, p. 346).

$\mathrm{Na}$ etapa das operações concretas, por volta dos sete anos, "[...] constatamos uma modificação fundamental no desenvolvimento da criança. Ela se torna capaz de certa lógica; ela se torna capaz de coordenar operações no sentido da reversibilidade, no sentido de conjunto [...] (PIAGET, 1974, p. 348). Por último, há, agora, a etapa das operações proporcionais ou formais, por volta dos dozes anos, em que

[...] a criança se torna capaz de raciocinar e de deduzir, não somente sobre objetos manipuláveis como bastões a serem ordenados, esses numerosos objetos a serem juntados, etc., mas se torna capaz de lógica e de raciocínio dedutivos, sobre hipóteses, sobre preposições (PIAGET, 1974, p. 350). 
Para Piaget (1974), o sujeito aprende porque se desenvolve e isso se encontra em oposição direta à concepção de ensino de Vygotsky (1988), em que o sujeito se desenvolve porque aprende, mais propriamente, é

[...] a noção de que os processos de desenvolvimento não coincidem com os processos de aprendizado. Ou melhor, o processo de desenvolvimento progride de forma mais lenta e atrás do processo de aprendizado; desta sequenciação resultam, então, as zonas de desenvolvimento proximal. Nossa análise modifica a visão tradicional, segundo a qual no momento em que uma criança assimila o significado de uma palavra, ou domina uma operação tal como a adição ou a linguagem escrita, seus processos de desenvolvimento estão basicamente completos (VYGOTSKY, 1988, p. 102).

Dentro desse quadro, estabelecido por Piaget (1974) e Vygotsky (1988), não se torna possível encontrar sentido algum em introduzir, no ensino da matemática, o uso da calculadora, uma vez que, no quarto ano do ensino fundamental, a criança se encontra, respectivamente, por um lado, na etapa das operações concretas, em que prevalece a lógica da reversibilidade na construção do conhecimento e, por outro lado, a zona proximal no seu pleno desenvolvimento das operações lógicas do pensamento, em que o uso da calculadora em nada colabora..

Outros teóricos do construtivismo também não condizem com a inserção desse equipamento eletrônico, pois, em Bruner (2001) ou Ausubel (2000), não se torna possível encontrar justificativa teórica que estabeleça algum fundamento para a referida prática educativa em termos de significação do conceito numérico no uso da máquina de calcular.

É passível de análise qual seria a justificativa do uso da máquina de calcular no ensino fundamental para que possa estar inserida, com alguma coerência, em relação à necessidade para o ensino da matemática. Reafirmamos que, em nossa interpretação, a indicação do uso da máquina de calcular ocorre por um modismo pedagógico pautado no senso comum, em que se devem inserir as crianças no uso desses objetos de tecnologias digitais. Entretanto, um olhar mais dedicado referente a esse assunto poderia indicar que as crianças já se encontram demasiadamente expostas às novidades de tecnologias digitais e caberia à unidade escolar realizar o trabalho de resgatar os elementos da cultura que se perdem nas práticas do cotidiano.

As interações do sujeito com os objetos deveriam, no ensino da matemática, favorecer a possibilidade efetiva na construção de estrutura do pensamento e, portanto, digitar, com a ponta dos dedos, o número e a operação matemática, na máquina, e, após, olhar o resultado no visor, o resultado em nada contribui com a formação da estrutura do pensamento. 0 aprender a usar as tecnologias digitais deveria ser substituído pelo aprender a pensar. 


\section{CONCLUSÃO - APRENDER A PENSAR E O TRABALHO DO PENSAMENTO NO ENSINO DA MATEMÁTICA}

Compreendemos que a opção entre utilizar ou não a máquina de calcular esteja diretamente relacionada com o conceito de educação. No caso específico, de um lado,isso é algo que se apresenta com a justificativa do seu uso como ganho de experiência no uso de tecnologias digitais e, por outro, em nossa concepção de educação, como a perda da experiência de vida com as tecnologias sociais.

A nossa concepção de educação associa a experiência de vida diretamente à experiência do trabalho do pensamento e, portanto, como em nossa interpretação, a indicação do uso da máquina de calcular no quarto ano do ensino fundamental se apresenta como uma deformidade em termos de processo formativo. Isso também se apresenta, de certo modo, no conjunto das práticas educativas no campo escolar em que os sujeitos individualizam e não se torna possível se encontrarem para trocarem palavras, ações e pensamentos (XXX - retirado a fonte 0 autor para não identificar, 2007).

Entre diversos espaços da sociedade, a escola se torna um aparelho que pode ser representado como uma tecnologia social de inserir o sujeito na vida coletiva entre todos os iguais, pois o seu funcionamento possui uma dinâmica específica de relações em que se pode compartilhar aquilo que é comum a todos.

Para mim, o trabalho na escola torna-se uma posição de responsabilidade do intelectual em assumir o caminho para a transmissão da cultura escolar do que é comum a todos,em vez de ficar preso a determinações que justificam, em parâmetros técnicos da legislação escolar, o uso da máquina de calcular como habilidade em tecnologia digital.

Compreendemos o aprender a aprender como caminho para aprender a pensar. Tornase evidente que fazer conta manualmente requer disciplina intelectual e o uso de máquinas de calcular que se inicia no terceiro ano e que se encontra presente no livro didático do quarto ano do ensino fundamental implica, diretamente, a precariedade do ensino da matemática e que pode se apresentar, inclusive, ao senso comum como perda da capacidade de pensar os números.

Em termos de teorias de aprendizagem, dever-se-ia buscar trabalhar os referidos conceitos com os alunos do curso de formação de professores na disciplina de Psicologia da Educação, que o sujeito aprende pelo desejo de desejo. Portanto, a matemática ou qualquer outra ciência se transmite pelo desejo daquele que anuncia a palavra para o outro. Torna-se comum, em decorrência do tecnicismo pedagógico, não encontrarmos o sujeito no campo escolar, que possa sustentar esse desejo perante a palavra que se profere para o outro e, 
portanto, o que pode prevalecer, no caso específico deste ensaio, seria o não querer pensar os números. Essa condição pode denominar-se como sendo a precarização da experiência do pensamento no ensino escolar.

Em relação a essa precarização da experiência do pensamento, não há como deixar de relatar algo que se encontra fora do assunto (GUATTARRI, 1981) como forma de deslocar o tema de análise para permitir que se apresente 0 desejo para se analisar o tema em questão. Portanto, referente à questão do gosto pelos números, lembro do tempo vivido, na infância, em que tivemos a oportunidade de passar diversas férias escolares na praia numa casa emprestada que ficava num lugar onde todas as demais casas não tinham muro e podíamos circular livremente pelo espaço de diversos terrenos das casas vizinhas. Isso se apresentava como uma característica única de coletividade, que permitia uma grande interação com todos que ali se encontravam. Lembro que os finais de semana se constituíam numa reunião com todos os vizinhos para o almoço coletivo. Todas as nossas atividades cotidianas se apresentam nas interações com o outro.

Atualmente, passados cinquenta anos, o lugar já não é o mesmo, pois todos os terrenos das casas se encontram completamente murados e os finais de semana se passam de modo individual, em que já não ocorrem mais as reuniões coletivas.

Esse relato vem indicar algo diretamente relacionado ao assunto do gosto pelos números, uma vez que o fenômeno atual que predomina em nossa existência seria a sociedade do indivíduo. Nesse estilo de vida, perde-se a experiência de vida e as tecnologias digitais se representam como lugar dos encontros coletivos nas redes sociais. Avaliamos que essa alteração no lugar do encontro do indivíduo com o coletivo virtual seja algo que determina, em grande parte, a perda na experiência do pensamento e, inclusive, a perda de experiência em pensar os números. Aqui, encontra-se uma posição de compreender a escola como lugar que possa realizar a reconstrução da experiência de vida perdida em termos de experiência do pensamento e que passa também pelo ensino e aprendizagem dos números em somar, subtrair, multiplicar e dividir e outras narrativas referentes ao ensino da matemática.

Não é problema algum no uso de tecnologias digitais, mas devem ser colocadas no ambiente escolar como elemento acessório para ampliação do pensamento crítico, para que, em estágio futuro, o aluno possa ampliar aquilo que já incorporou em termos da dimensão numérica como raciocínio lógico. No caso contrário, em que precocemente se utiliza a máquina de calcular para o ensino das operações fundamentais para crianças, o que pode prevalecer é a estagnação no modo de pensar os números e alienar o sujeito perante os conceitos da matemática. 
No caso específico da queixa do pai, fica evidente o bom senso de que as crianças, no quarto ano do ensino fundamental, não deveriam usar a máquina de calcular, pois se encontram no momento de se inserir na lógica do pensamento matemático. Espera-se da escola construir, de modo responsável, os diversos conceitos que compõem a cultura escolar.

Um professor de matemática deveria se perguntar qual significado tem para 0 aluno a máquina de calcular ao apresentar, em seu visor, o resultado da operação matemática? Essa lógica de máquina e resultado está incorporada em todos os processos de ensino e aprendizagem em que os alunos decorrem as fórmulas da equação sem compreender as estruturas lógicas que elas representam. São por esses e outros tantos demais motivos que 0 Brasil fica em quase último lugar no PISA (BRASIL, 2020a) e isso, por si só, já seria suficiente para responder à nossa recusa no uso da máquina de calcular no quarto ano do ensino fundamental. Isso também, por si só, responde que não ocorre coerência no uso da máquina de calcular para as crianças aprenderem a matemática. Em termos de problema no ensino, pode-se perguntar: seria possível conhecer sem aprender, aprender sem saber e saber sem conhecer? Tudo indica que sim, pois os processos atuais de escolarização tornam as crianças e jovens conhecedores sem causa, figuras desconectadas com a vida, enfim, conhecem e não aprendem; aprendem, mas não sabem e, por fim, sabem, mas não conhecem. De certo modo, tem-se instituída, no ambiente escolar, uma completa confusão do que seria a tarefa de educar e isso acaba também por eliminar o papel do educador na função da mestria perante o saber.

Dir-se-ia que a grande diferença entre a aprendizagem destituída de significado e 0 conhecimento significativo para o sujeito seja a possibilidade de se estabelecer determinados graus de implicação do sujeito perante sua própria relação educativa com a vida. Assim, o sujeito inserido no vínculo educativo seria o resultado do modo como elabora as relações entre significante e significado que torna o saber elemento estruturante para uma condição de implicância e isso é também válido para o saber científico.

Conclui-se que inserir precocemente o uso da máquina de calcular, no ensino da matemática, não se encontra fundamentado no campo das teorias de aprendizagem e, portanto, isso pode indicar apenas elemento de modismo pedagógico relacionado ao uso das tecnologias digitais. Torna-se preocupante a precarização do ensino escolar, em que os resultados dessas ações do modismo pedagógico podem impedir a constituição do sujeito reflexivo no saber científico, principalmente, no permanente trabalho na experiência do pensamento como lugar do aprender a pensar e, no caso especifico, a aprender a pensar os números. Em termos de aprender a pensar, espera-se que, em algum dia, possamos encontrar o Brasil próximo do primeiro lugar na avaliação do PISA em diversas áreas do conhecimento, mas, em nossa 
compreensão, isso não deve passar pelo uso de máquina de calcular para ensinar matemática para as crianças.

\section{REFERÊNCIAS}

ARENDT, H. Entre o passado e o futuro. Trad. Mauro W. Barbosa. São Paulo: Perpesctiva, 2011.

AUSUBEL, D. P. Aquisição e retenção de conhecimentos: uma perspectiva cognitiva. Trad. Lígia Teopisto. Lisboa: Plátano Edições Técnicas, 2000.

BERMÚDEZ, A. C. Pisa: Brasil fica entre piores, mas à frente da Argentina. Educação. Disponivel em:<https://educacao.uol.com.br/noticias/2019/12/03/pisa-brasil-fica-entre-pioresmas-a-frente-da-argentina-veja-ranking.htm>. Acesso em: 29 abr. 2020.

BRASIL. Lei n. 9.394. In: BRASIL. Diário Oficial. Ano CXXXIV, n. 248, 23 dez. 1996.

BRASIL. Base Nacional Comum Curricular (BNCC). In: BRASIL. Ministério da Educação, Sem data.

BRASIL. Programa Internacional de Avaliação de Estudantes (Pisa). In: BRASIL. Instituto Nacional de Estudos e Pesquisas Educacionais (INEP). Disponível em:<http://download.inep.gov.br/acoes_internacionais/pisa/documentos/2019/relatorio_PISA_20 18_preliminar.pdf>. Acesso em: 18 maio 2020a.

BRASIL. PNLD. In: BRASIL.Ministério da Educação. Disponível em: $<$ http://portal.mec.gov.br/busca-geral/318-programas-e-acoes-1921564125/pnld439702797/12391-pnld>. Acesso em: 25 maio 2020b.

BRUNER, J. A cultura da educação. Trad. Marcos A. G. Domingues. Porto Alegre: Artmcd Editora, 2001.

DIAS, S. M. China: tradição e inovação - perspectivas sobre a educação básica e o ensino médio na China. In: BRASIL. Mundo Afora. Brasilia: Ministério das Relações Exteriores, 2004.

GUATTARI, F. Revolução Molecular: pulsações políticas do desejo. Trad. Suely Belinha Rolnik. São Paulo: Brasiliense, 1981.

KISTEMANN, M. A. O uso da calculadora nos anos iniciais do ensino fundamental. Bolema, Rio Claro, v. 28, n. 50, p. 1579-1582, Dec. 2014 . Disponível em:

$<$ http://www.scielo.br/scielo.php?script=sci_arttext\&pid=S0103-

636X2014000301579\&lng=en\&nrm=iso>. Acesso em: 15 jun. 2020.

PIAGET, J. A Epistemologia Genética. Trad. Nathanael C. Caixeiro. São Paulo: Abril Cultural, 1974.

PINTO, A E S. Entenda por que quase todos os países fecharam escolas. In:Folha de S. Paulo. Disponível em: <https://www1.folha.uol.com.br/equilibrioesaude/2020/03/entenda-por-que-quasetodos-os-paises-fecharam-escolas.shtml>.Acesso em: 19 maio 2020. 
XXX - retirado a fonte o autor para não identificar. 2007.

XXX - retirado a fonte o autor para não identificar. 2018.

SEM AUTOR. Govemo de SP anuncia suspensão de aulas e eventos com mais de 500 pessoas. Portal do Governo, São Paulo. Disponivel em: <https://www.saopaulo.sp.gov.br/spnoticias/saude-e-centro-decontingencia-atualizam-cenario-sobre-novo-coronavirus-em-sp/>. Acesso em: 20 maio 2020.

VYGOTSKY, L. S. Formação social da mente. Trad. José Cipolla Neto. São Paulo: Martins Fontes, 1988. 